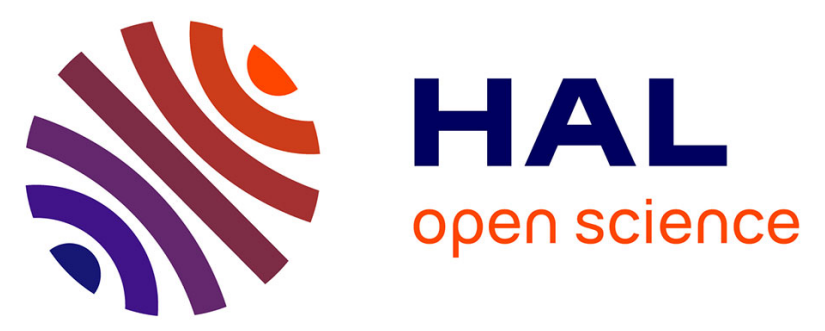

\title{
Do immigrants from Turkey, Pakistan and Yugoslavia receive adequate medical treatment with beta-blockers and statins after acute myocardial infarction compared with Danish-born residents? A register-based follow-up study
}

Nana Folmann Hempler, Finn Diderichsen, Finn Breinholt Larsen, Steen Ladelund, Torben Jørgensen

\section{- To cite this version:}

Nana Folmann Hempler, Finn Diderichsen, Finn Breinholt Larsen, Steen Ladelund, Torben Jørgensen. Do immigrants from Turkey, Pakistan and Yugoslavia receive adequate medical treatment with betablockers and statins after acute myocardial infarction compared with Danish-born residents? A register-based follow-up study. European Journal of Clinical Pharmacology, 2010, 66 (7), pp.735742. 10.1007/s00228-010-0816-3 . hal-00586132

\author{
HAL Id: hal-00586132 \\ https://hal.science/hal-00586132
}

Submitted on 15 Apr 2011

HAL is a multi-disciplinary open access archive for the deposit and dissemination of scientific research documents, whether they are published or not. The documents may come from teaching and research institutions in France or abroad, or from public or private research centers.
L'archive ouverte pluridisciplinaire HAL, est destinée au dépôt et à la diffusion de documents scientifiques de niveau recherche, publiés ou non, émanant des établissements d'enseignement et de recherche français ou étrangers, des laboratoires publics ou privés. 


\title{
Do immigrants from Turkey, Pakistan and Yugoslavia receive adequate medical treatment with beta-blockers and statins after acute myocardial infarction compared with Danish-born residents? A register-based follow-up study
}

\author{
Nana Folmann Hempler • Finn Diderichsen • \\ Finn Breinholt Larsen • Steen Ladelund • \\ Torben Jørgensen
}

Received: 15 January 2010 / Accepted: 16 March 2010/Published online: 15 April 2010

(C) Springer-Verlag 2010

\begin{abstract}
Purpose We undertook a study investigating whether immigrants from Turkey, Pakistan and Yugoslavia received adequate medical treatment with beta-blockers and statins after acute myocardial infarction (AMI) when compared with Danish-born residents and explored whether associations between patient origin and medical treatment were mediated by socioeconomic status (SES).

Methods This register-based follow-up study consisted of individuals $>17$ years of age, admitted to hospital with AMI between 2001 and 2005 ( $n=25$ 443). Danish-born residents were compared with immigrants from Turkey, Pakistan and Yugoslavia. Individuals were identified by civil registration number, and data were obtained through linkage to the national registers of hospitalisations and drug prescriptions. Odds of initiating treatment and hazard ratios (HR) of
\end{abstract}

N. Folmann Hempler $(\bowtie)$

Research Centre for Prevention and Health,

Capital Region of Denmark, Glostrup University Hospital,

Building 84/85,

DK-2600 Glostrup, Denmark

e-mail: nabf@glo.regionh.dk

S. Ladelund · T. Jørgensen

Research Centre for Prevention and Health,

Capital Region of Denmark, Glostrup University Hospital,

Glostrup, Denmark

F. Diderichsen

Department of Social Medicine, Institute of Public Health,

University of Copenhagen,

DK-1014 Copenhagen K, Denmark

F. B. Larsen

Centre of Public Health, Central Denmark Region,

DK-8200 Aarhus N, Denmark terminating treatment were estimated. Mediators such as income and employment were included in the models.

Results Pakistanis were less likely than Danish-born residents to initiate treatment with beta-blockers after AMI [odds ratio 0.52 ; 95\% confidence interval (CI) $0.34-0.80]$. Immigrants from Turkey (HR 1.36; 95\% CI 1.07-1.73) and Pakistan (HR 1.59 ; $95 \%$ CI $1.21-2.08$ ) were more likely to terminate treatment with beta-blockers before being recommended to do so. Estimates did not change markedly when income and education were included in the models.

Conclusions The results of this study suggest that immigrants from Pakistan and Turkey do not receive adequate medical treatment with beta-blockers after a first AMI compared with Danish-born residents. Mediators such as income and employment may not be sufficient indicators of SES when the effect of patient origin on medical treatment is explored. A lower SES of immigrants, communication problems between doctor and patient and doctors' attitudes towards immigrants may explain ethnic differences in medical treatment after AMI.

Keywords Acute myocardial infarction - Beta-blockers . Immigrants $\cdot$ Socioeconomic status $\cdot$ Statins

\section{Introduction}

Immigrants and their descendants comprise a growing proportion of the Danish population-9.5\% in 2009 [1]. Nearly two thirds of these ethnic groups originate from middle- and low-income countries. Immigrant workers arrived in Denmark during the 1960s and the early 1970s, particularly from Pakistan, Turkey, Morocco and the former 
Socialist Federal Republic of Yugoslavia (Yugoslavia), due to a shortage of work in their home countries. The 'guest workers' were invited to Denmark because of the economic boom during this period.

European studies have shown that mortality and the incidence of cardiovascular disease vary by ethnic group [2-5]. A large Danish register-based study found that hospital services related to cardiovascular disease also vary between the nine largest ethnic groups from non-western countries [6]. In particular, immigrants from Pakistan, Turkey and Yugoslavia were found to have an increased use of hospital services compared to Danish-born residents, but they were less likely to buy prescription drugs for antihypertensive and lipid-lowering treatments. This may indicate that medical treatment does not match the increased need of the immigrants and may possibly be explained by the lower socioeconomic (SES) status of immigrants. Results from recent studies have shown that individuals with a low SES have a poorer adherence regarding treatment with beta-blockers and statins after acute myocardial infarction (AMI) [7, 8], and some studies have also indicated that ethnic differences in cardiovascular disease are caused by differences in SES [9-12].

In the study reported here, we examined the associations between patient origin and the initiation and termination of treatment with beta-blockers and statins after AMI and explored whether these associations were mediated by income and employment. Danish-born residents were compared with immigrants from Turkey, Pakistan and the former Yugoslavia.

\section{Methods}

\section{Study population}

We undertook a register-based follow-up study of a population consisting of Danish-born residents and immigrants from Turkey, Pakistan and the former Socialist Federal Republic of Yugoslavia (Yugoslavia) The inclusion criteria were: age $>17$ years; (2) resident in one of two regions in Denmark (the Capital Region and Central Denmark Region) on 1 January 2001 ( $n=2313$ 525); (3) admission to hospital with a first AMI between 2001 and $2005(n=25443)$. The population was identified in the civil registration system in which all residents in Denmark are registered by a unique 10 digital number, making linkage across time and registers possible.

\section{Medical guidelines}

Treatment with statins and beta-blockers after AMI reduces the risk of recurrent AMI and increases survival; therefore, international and national guidelines recommend treatment after AMI [13-15]. Danish guidelines recommend the use of beta-blockers for at least 2 years after AMI and lifelong treatment with statins [13]. Guidelines also include treatment with aspirin. However, it is not possible to identify aspirin in the registers as it is an over-the-counter product in Denmark. Medical treatment after AMI is provided by the general practitioner, or the patient is followed ambulant in rehabilitation programmes. The Danish health care system is built on the Nordic welfare model in which citizens have free access to health care. In Denmark, patients have medical expenditures partially reimbursed by the public health insurance when the amount exceeds approximately 70 Euros per year. When medical expenditures increase, the amount that is reimbursed is likewise increased.

Outcome data

Information on hospital admissions related to a first AMI between 2001 and 2005 was obtained from the Danish National Patient Registry. The AMI was identified in the register as the primary diagnosis by the International Classification of Diseases (ICD 10, codes I21, I22). Information on deaths was obtained through linkage to the Register for Population Statistics at Statistics Denmark. Individuals that received treatment with beta-blockers and statins 90 days before AMI or with a previous history of AMI between 1997 and 2000 were excluded.

Statins and beta-blockers were identified in the National Prescription Register (Registry of Medical Product Statistics), which contains information on all outpatient prescriptions in Denmark using the Anatomical Therapeutic Chemical Classification System (ATC codes). We calculated the length of time from when a prescription was redeemed to the time when the defined daily dose (DDD) had expired plus a grace period of $x$ days [16]. As the grace period ended and no new prescription had been redeemed, the patient was classified as having terminated treatment. The DDD is the assumed average maintenance dose per day for a drug used for its main indication in adults [17].

Treatment initiation, with statins (code C10A) and betablockers (code $\mathrm{C} 07$ ), was defined as at least one redeemed prescription at a pharmacy within 14 days, using the 2007 version of the ATC/DDD classification. Treatment termination was defined as not redeeming a new prescription within 90 days after the defined daily doses had expired in those who initiated treatment within 14 days.

\section{Covariates}

Data on birth, sex, patient origin, income, employment and migrations was obtained from the Demographic Database and the Integrated Database for Labour Marked Research (IDA) at Statistics Denmark. All analyses were adjusted for 
age and sex. Age was included as a continuous variable. Immigrants were defined as individuals born in foreign countries to parents also born in a foreign country [1]. Immigrants from the now former Yugoslavia did not include refugees from the Yugoslavian civil war because refugees and labour migrants have a different migration history. Differentiation was possible as individuals arriving to Denmark after the civil war were registered under a different country origin.

Information on annual income and employment consisted of baseline data from 2001. Annual income was considered to be the wages from earnings and social transfers registered by tax authorities (using a currency rate $100 \mathrm{DKK}=13.44 \mathrm{EUR}$ ). Based on annual income, the entire study population was categorised into a low income group (<20 158 EUR), a middle income group (20 159-33 597 EUR) and a high income group (> 33598 EUR). Income was included as a continuous variable. Information on employment was taken from registers and was used to classify the entire study population into groups, namely, the employed, the unemployed and the retired. Income and employment were included as mediators of the effect of patient origin on treatment with beta-blockers and statins.

\section{Statistical analysis}

We examined three models of treatment initiation and treatment termination (Diagram 1). The causal diagram guided the analyses. In model 1 we estimated the total effect of patient origin on medical treatment, which requires adjustment for confounders but not mediators. In model 2-3 we estimated the controlled direct effect of patient origin on medical by maintaining the mediator at a constant level (by adjusting for it). We included one mediator in each model. When including income as a mediator, this opened the pathway for confounding by employment (Diagram 1). Therefore, employment was also included in model 3. Furthermore, we tested associations between income/employment and treatment initiation and termination with beta-blockers and statins after AMI for the entire population.

Model 1: total effect of patient origin on medical treatment

Confounders: age and sex

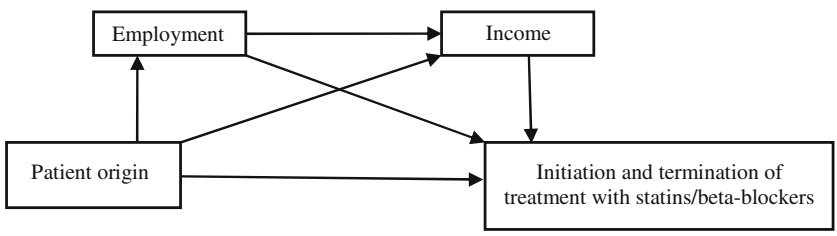

Diagram 1 Causal relations between patient origin and treatment with statins and beta-blockers
Model 2: controlled direct effect of patient origin on medical treatment

Mediator: employment

Confounders: age and sex

Model 3: controlled direct effect of patient origin on medical treatment

Mediator: income

Confounders: age, sex and employment

In the analysis of treatment initiation of beta-blockers and statins, we used logistic regression models to estimate the odds of redeeming a prescription within 14 days after discharge. Sensitivity analyses for treatment initiation after 7 and 30 days were also performed.

We used survival analyses with Cox regression to analyse the persistence with treatment. We evaluated the hazard ratios (HR) of terminating treatment with betablockers within 2 and 5 years after a AMI, and statins within 5 years. Sensitivity analyses were carried out for 120 and 180 days after the DDD had expired. In all analyses, individuals were censored if they died, migrated or reached the end of the observation period. Danish-born residents were used as the reference category.

As model control we carried out the Hosmer and Lemeshow goodness-of-fit test for the logistic regression models. Models fitted better when age was transformed by the square of age. For models on beta-blockers, an interaction term including sex and employment was included, and model assumptions were satisfied. We also tested if the assumptions of proportional hazard were fulfilled in the survival analyses. For models with statins, assumptions were fulfilled; for beta-blockers, the models fitted better when we stratified for sex and included age as a time-dependent variable in the model. All analyses were performed using SAS ver. 9.1 (SAS Institute, Cary, NC).

\section{Results}

Men were overrepresented in all groups but compared with Danish-born residents, the distribution was particularly skewed in immigrants from Turkey (Table 1). Danish-born residents were more likely to be older than the immigrants, while immigrants from Turkey had lower income. In addition, immigrants were more likely than Danish-born residents to be unemployed. Between 2001 and 2005 there were 25443 hospital admissions due to a first AMI in the two study areas (Table 2). Among these, 88\% $(n=22335)$ were discharged alive. Immigrants constituted just over $1 \%$ $(n=322)$ of the total dataset.

An assessment of the crude figures reveals that a relatively large percentage of all groups initiated treatment with beta-blockers within 14 days of a first AMI (74.1- 
Table 1 Characteristics of patients admitted to hospital after a first acute myocardial infarction $^{\mathrm{a}}$ according to patient origin

$* P<0.0001,{ }^{* *} P<0.001$,

$* * * P<0.01$

Values given in parenthesis are percentages

${ }^{\text {a }}$ Individuals with a prior acute myocardial infarction (AMI)

between 1997 and 2000 were excluded

\begin{tabular}{lcclc}
\hline Patient characteristics & Danish-born residents & Turks & Pakistanis & Yugoslavians \\
\hline Sex $(n)$ & & & & \\
$\quad$ Male & $15449(61.5)$ & $120(81.1)^{*}$ & $88(75.9)^{* * *}$ & $40(69.0)$ \\
$\quad$ Female & $9672(38.5)$ & $28(18.9)$ & $28(24.1)$ & $18(31.0)$ \\
Age (years) & $2193(8.7)$ & & & \\
$\quad 18-49$ & $4141(16.5)$ & $43(29.1)^{*}$ & $32(27.6)^{*}$ & $15(25.9)^{*}$ \\
$50-59$ & $18787(74.8)$ & $64(43.2)$ & $41(35.3)$ & $24(41.4)$ \\
$>60$ & $14080(56.1)$ & $106(71.6)^{* *}$ & $77(66.4)$ & $43(74.1)$ \\
Income (in EUR) & $5687(22.6)$ & $27(18.2)$ & $19(16.4)$ & $6(10.3)$ \\
$<20158$ & $5354(21.3)$ & $15(10.1)$ & $20(17.2)$ & $9(15.5)$ \\
$20159-33597$ & & & & $18(31.0)^{*}$ \\
$>33598$ & $6385(25.4)$ & $40(27.0)^{*}$ & $42(36.2)^{*}$ & $14(24.1)$ \\
Employment $(n)$ & $2118(8.4)$ & $34(23.0)$ & $32(27.6)$ & $19(32.8)$ \\
$\quad$ Employed & $16156(64.3)$ & $61(41.2)$ & $23(19.8)$ & $7(12.1)$ \\
Not employed & $462(1.8)$ & $13(8.8)$ & $19(16.4)$ & \\
Retired & & & &
\end{tabular}

$85.7 \%$ ) (Table 2). After 30 days, the percentages varied between 77.7 and $87.1 \%$. Among the four population groups analysed, Pakistanis had the lowest percentage of individuals in treatment. We found a greater variation within the groups in relation to initiation of treatment with statins (60.8-82.1\% within 14 days), with Danish-born residents having the lowest percentage of individuals in treatment and Yugoslavians having the highest percentage.

Using Danish-born residents as a reference, Pakistanis had lower odds of initiating treatment with beta-blockers (Table 3), whereas immigrants from Turkey and Yugoslavia had insignificantly higher odds. A slight increase in the odds ratios were seen in all immigrant groups when income and employment were included in the model (Models 2 and 3).We also found that the odds of initiating treatment were significantly lower in the low income group compared with the high income group across the entire study population [odds ratio (OR) 0.77 ; 95\% confidence interval (CI) 0.70 0.85]. The odds of initiating treatment were lower among the unemployed (OR 0.60; 95\% CI 0.53-0.69) and the retired (OR 0.87; 95\% CI 0.76-98) than among the employed (not reported in table).

Yugoslavians had higher odds of initiating treatment with statins than Danish-born residents, although the

Table 2 Admissions, person-years and treatment initiation according to patient origin

\begin{tabular}{|c|c|c|c|c|}
\hline Variables & Danish-born residents & Turks & Pakistanis & Yugoslavians \\
\hline Individuals admitted to hospital after a first $\mathrm{AMI}^{\mathrm{a}}, n$ & 25121 & 148 & 116 & 58 \\
\hline Individuals discharged alive, $n(\%)$ & $22028(87.7)$ & $139(93.9)$ & $112(96.6)$ & $56(96.6)$ \\
\hline \multicolumn{5}{|l|}{ Total time at risk ( $n /$ years at risk) } \\
\hline Beta-blockers & $17371 / 23770$ & $119 / 150$ & $83 / 100$ & $48 / 64$ \\
\hline Statins & $13387 / 24990$ & $98 / 150$ & $87 / 176$ & $46 / 88$ \\
\hline \multicolumn{5}{|l|}{ Treatment initiation of beta-blockers (days) ${ }^{b}$} \\
\hline 7 & $77.7 \%$ & $83.5 \%$ & $70.5 \%$ & $82.1 \%$ \\
\hline 14 & $78.9 \%$ & $85.6 \%$ & $74.1 \%$ & $85.7 \%$ \\
\hline 30 & $80.2 \%$ & $87.1 \%$ & $77.7 \%$ & $85.7 \%$ \\
\hline \multicolumn{5}{|l|}{ Treatment initiation of statins (days) ${ }^{b}$} \\
\hline 7 & $59.6 \%$ & $68.4 \%$ & $76.8 \%$ & $80.4 \%$ \\
\hline 14 & $60.8 \%$ & $70.5 \%$ & $77.7 \%$ & $82.1 \%$ \\
\hline 30 & $62.2 \%$ & $71.9 \%$ & $81.3 \%$ & $82.1 \%$ \\
\hline
\end{tabular}

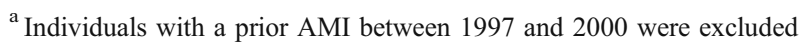

${ }^{\mathrm{b}}$ Days from discharge to redeemed prescription in those discharged alive with no previous cardiovascular disease who did not receive medical treatment 90 days prior to the AMI 
Table 3 Initiation of treatment according to patient origin ${ }^{\mathrm{a}}$

\begin{tabular}{|c|c|c|c|c|c|c|}
\hline \multirow[t]{2}{*}{ Patient origin } & \multicolumn{3}{|l|}{ Beta-blockers } & \multicolumn{3}{|l|}{ Statins } \\
\hline & $\begin{array}{l}\text { Model } 1^{\mathrm{a}} \\
(n=22335)\end{array}$ & $\begin{array}{l}\text { Model } 2^{\mathrm{b}} \\
(n=21859)\end{array}$ & 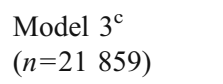 & $\begin{array}{l}\text { Model } 1^{\mathrm{a}} \\
(\mathrm{N}=22335)\end{array}$ & 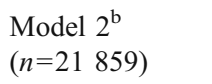 & 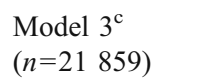 \\
\hline Danish-born residents & 1 & 1 & 1 & 1 & 1 & 1 \\
\hline Turks & $1.15(0.72-1.86)$ & $1.30(0.78-2.15)$ & $1.31(0.79-2.17)$ & $0.84(0.58-1.23)$ & $0.90(0.60-1.33)$ & $0.93(0.63-1.38)$ \\
\hline Yugoslavians & $1.13(0.53-2.40)$ & $1.24(0.55-2.78)$ & $1.25(0.56-2.80)$ & $1.53(0.76-3.08)$ & $1.42(0.70-2.89)$ & $1.46(0.71-2.97)$ \\
\hline Pakistanis & $0.52(0.34-0.80)$ & $0.60(0.37-0.97)$ & $0.61(0.38-0.98)$ & $1.06(0.67-1.66)$ & $1.50(0.88-2.56)$ & $1.55(0.91-2.64)$ \\
\hline
\end{tabular}

The values represent odds ratio (OR) estimates, with the $95 \%$ confidence interval (CI) given in parenthesis

${ }^{a}$ Model 1: age and sex

${ }^{\mathrm{b}}$ Model 2: age, sex and employment (mediator)

${ }^{\mathrm{c}}$ Model 3: age, sex, employment and income (mediator)

difference was not statistically significant (Table 3, model 1). No significant differences were found between Turks/ Pakistanis and Danish-born residents (Table 3, model 1). In model 2 and 3, where income and employment were included, the odds ratios of initiating treatment increased in immigrants from Pakistan, but the estimates remained insignificant. The odds of treatment initiation was significantly lower in the low income group compared with the high income group (OR $0.82 ; 95 \%$ CI $0.75-0.89$ ). The odds of treatment initiation was lower among the unemployed (OR 0.83; 95\% CI 0.74-0.93), than among the employed (not reported in table).

Immigrants had higher hazard ratios for terminating treatment with beta-blockers within a 2-year period than Danish-born residents, although the difference was only significant for Turks and Pakistanis (Table 4). Analysis of the treatment termination with beta-blockers at the 5-year follow-up revealed no change in the results (Table 5). Estimates were unchanged when income and employment were included in the model. The low income group (HR $0.91 ; 95 \%$ CI $0.85-0.97$ ) and the middle income group (HR 0.93 ; $95 \%$ CI $0.87-0.99$ ) had, compared with the high income group, lower hazard ratios of treatment termination within a 2-year period. Employment was not associated with a patient terminating treatment prior to being recommended to do so (not reported in table).
With respect to treatment with statins, immigrants had higher hazard ratios for terminating treatment within a 5-year period than Danish-born residents, but the differences in estimates are insignificant (Table 5). The estimates attenuated when mediators such as income and employment were included in the model, particularly in Yugoslavians. Employment was not associated with terminating treatment before recommendation. Compared with the high income group, the middle income group (HR 1.19; 95\% CI 1.031.38 ) and the low income group (HR 1.35; 95\% CI 1.02-1.55) had higher hazard ratios of terminating treatment within a 5-year period (not reported in table).

\section{Discussion}

In this register-based study, we have demonstrated differences in treatment with beta-blockers and statins after a first AMI according to patient origin. Pakistanis had lower odds of initiating treatment with beta-blockers compared with Danish-born residents, whereas Turks and Yugoslavians had higher odds, although the estimates were not significantly different. No significant differences were found in terms of treatment initiation with statins, but Yugoslavians were more likely to initiate treatment than Danish-born residents. Immigrants were more likely than Danish-born

Table 4 Termination of treatment with beta-blockers before expiration of a 2-year period according to patient origin ${ }^{\mathrm{a}}$

\begin{tabular}{llll}
\hline Patient origin & Model 1 $(n=18243)$ & Model 2 $(n=17844)$ & Model 3 $(n=17844)$ \\
\hline Danish-born residents & 1 & 1 & 1 \\
Turks & $1.36(1.07-1.73)$ & $1.38(1.08-1.77)$ & $1.39(1.09-1.78)$ \\
Yugoslavians & $1.18(0.79-1.77)$ & $1.08(0.69-1.69)$ & $1.08(0.69-1.78)$ \\
Pakistanis & $1.59(1.21-2.08)$ & $1.38(1.16-2.07)$ & $1.56(1.16-2.08)$ \\
\hline
\end{tabular}

Values are shown as hazard ratio (HR) estimates, with the $95 \% \mathrm{CI}$ in parenthesis

See Table 3 for definition of models

${ }^{\mathrm{a}}$ In patients who initiated treatment 
Table 5 Termination of treatment before expiration of a 5-year period according to patient origin ${ }^{\mathrm{a}}$

\begin{tabular}{|c|c|c|c|c|c|c|}
\hline \multirow[t]{2}{*}{ Patient origin } & \multicolumn{3}{|l|}{ Beta-blockers } & \multicolumn{3}{|l|}{ Statins } \\
\hline & $\begin{array}{l}\text { Model } 1 \\
(n=18243)\end{array}$ & $\begin{array}{l}\text { Model } 2 \\
(n=17844)\end{array}$ & $\begin{array}{l}\text { Model } 3 \\
(n=17844)\end{array}$ & $\begin{array}{l}\text { Model } 1 \\
(n=13928)\end{array}$ & $\begin{array}{l}\text { Model } 2 \\
(n=13575)\end{array}$ & $\begin{array}{l}\text { Model } 3 \\
(n=13575)\end{array}$ \\
\hline Danish-born residents & 1 & 1 & 1 & 1 & 1 & 1 \\
\hline Turks & $1.39(1.10-1.76)$ & $1.44(1.13-1.82)$ & $1.39(1.09-1.79)$ & $1.54(0.94-2.52)$ & $1.42(0.84-2.41)$ & $1.37(0.80-2.32)$ \\
\hline Yugoslavians & $1.17(0.78-1.75)$ & $1.08(0.69-1.69)$ & $1.08(0.69-1.70)$ & $1.45(0.69-3.04)$ & $1.17(0.49-2.81)$ & $1.13(0.47-2.72)$ \\
\hline Pakistanis & $1.61(1.23-2.11)$ & $1.55(1.16-2.07)$ & $1.56(1.16-2.08)$ & $1.19(0.67-2.10)$ & $1.10(0.59-2.06)$ & $1.07(0.57-1.99)$ \\
\hline
\end{tabular}

Values are shown as hazard ratio (HR) estimates, with the $95 \%$ CI in parenthesis

See Table 3 for definition of models

${ }^{\mathrm{a}}$ In patients who initiated treatment

residents to terminate treatment with beta-blockers within a 2-year period; however, the difference was only significant among Turks and Pakistanis. The results were the same at the 5-year follow-up. In addition, immigrants had a nonsignificant trend with respect to treatment termination with statins compared with Danish-born residents. The associations may be insignificant because of type 2 errors resulting from the small sample size. No notable differences were observed in the analyses of initiation and persistence when mediators were included in models 2 and 3. Patients in the high income group were more likely to initiate treatment with statins and beta-blockers and less likely to terminate treatment with statins than those of the low and middle income groups. However, patients in the high income group were more likely to terminate treatment with beta-blockers prior to being recommended to do so than those in the low income group.

The pertinent question is whether the Danish health care system is delivering equitable health care to immigrants when it comes to treatment with beta-blockers and statins after AMI? Formal and informal barriers may explain immigrant-related differences in medical treatment.

Formal barriers may comprise user payment and access to medical treatment in the country of birth. In Denmark, visits to general practitioners and rehabilitation are free of charge, but chronic patients receive only partial reimbursement for medical expenses. Therefore, low SES of immigrants compared to that of Danish-born residents may partially explain the differences. We found that while patients in the high income group were more likely to initiate medical treatment, they were also more likely to terminate treatment with betablockers before being recommended to do so. In a recent Danish study, the authors also suggested that individuals with a low income less frequently initiated treatment with betablockers and statins after AMI and had worse long-term persistence with statins [7]. In accordance with our findings, the results of this Danish study also suggested that the low income group had better persistence with beta-blockers compared with the high income group. The results of another Danish study suggested that compared with basiclevel workers, a higher proportion of top-managers with cardiovascular disease received treatment with statins [8].

Although the mediators were associated with outcome and patient origin, estimates did not change markedly when we included income and employment as mediators in the models. However, particularly in Yugoslavians, estimates on treatment termination with statins decreased when mediators such as income and employment were included in the model, although the trend was non-significant. In the analyses of treatment initiation, a slight increase in the odds ratios was seen in the immigrant groups when income and employment were included in models 2 and 3. Education may be a more sufficient indicator of SES due to the fact that a high percentage of the population was retired and, therefore, had a low income and was not employed. However, for a considerable number of immigrants, the registers do not contain information on educational level achieved in the country of birth; this is also true for Danishborn residents born before 1920 .

Communication problems, including language difficulties and the doctor's attitude towards immigrants, may constitute informal barriers. It is possible that communication problems caused by language barriers affect the patient's awareness of the benefits and side effects of the drugs. However, doctor-patient communication goes further than language. A Dutch review suggested that general practitioners behave less affectively when interacting with ethnic minorities compared with native Dutch Patients and that ethnic minorities seem to be less assertive and affective during the medical encounter [18]. The results of another Dutch study suggested that consultations with immigrant patients (particularly those from Turkey and Morocco) were well over 2 min shorter than those with Dutch patients [19].

Published studies that compare immigrants and the native population in terms of treatment with beta-blockers and statins after AMI are sparse. One Swedish study 
showed that immigrants from outside the EU25 countries had a tendency towards a lower use of the recommended drugs after AMI than native Swedish nationals [20]. However, immigrant groups were not specified in this study and, therefore, it was not possible to explore ethnic differences in medical treatment after AMI. A number of studies carried out in the USA have also shown ethnic differences in cardiovascular medical treatment, although African Americans are not considered immigrants. One such study found that Caucasians showed a better adherence to cardiac medications than African Americans [21], while another showed that African Americans had poor blood pressure relative to Caucasians. The authors of this study suggested that the observed ethnic difference in blood pressure control was due to medication non-adherence [22]. In contrast, an African American study found no ethnic differences in the adherence of drugs in relation to blood pressure, although African Americans did receive better counselling on hypertension care and medication adherence [23]. It should be noted that it was difficult to compare these findings due to the differences in patient origin, migration history and the structure of the health care system.

Our study has some noteworthy limitations. First, the sample size was small in terms of immigrant numbers $(n=$ 322), and the employment data contained some notable gaps (Table 1). Secondly, only individuals with a previous AMI between 1997 and 2000 were excluded from the study. Consequently, some of the patients may have had an AMI before 1997, but going back further in time would have been problematic in relation to immigrants because we included individuals who immigrated before 2001. Thirdly, we did not consider subgroups of drugs and combinations of different drugs. Furthermore, one must consider the inability to determine if the patient actually consumed the dispensed drugs or not. However, the use of the registers eliminated recall-bias or an overestimation of adherence. Finally, we only had information on the redeemed drugs, and this leaves some uncertainty on the concordance between prescribed drugs and redeemed drugs. Another important point to be considered is whether the observed differences among the groups in terms of treatment with beta-blockers and statins were a result of treatment in Denmark or due to the purchase of non-registered drugs over the Internet/in the immigrants' countries of birth, which could result in differential misclassification of outcome. However, a Dutch study found that only a small number of ethnic minorities reported buying drugs in their country of origin that were prescription drugs in the Netherlands [24].

The main strength of this study is its register-based design with a follow-up period of 5 years. Furthermore, the validity of the AMI was high as it was based on the
National Patient Registry and the Register for Population Statistics [25]. The use of data on income and employment at the individual level also strengthened the study. We decided that the elapse from discharge to initiation of treatment should be relatively short (14 days) because this enabled us to minimise the risk of deaths, migration and recurrent AMI before prescription redemption. Treatment termination was defined as 90 days after the DDD had expired, and analyses at 120 and 180 days suggested that the data were robust. The results may be generalised to other settings that have similar drug-reimbursement policies to Denmark; however, similar ethnic groups in different countries may not be comparable due to differences in SES and migration history.

\section{Conclusion}

The results of this study suggest that immigrants from Pakistan initiate preventive treatment with beta-blockers after an initial AMI less frequently than Danish-born residents. The immigrants of our patient cohort were more likely to terminate treatment with beta-blockers before being recommended to do so; however, this was only significant for Turks and Pakistanis. No notable differences in the associations were found when income and education were included in the models, which may be due to small sample size and because income and employment may not be sufficient indicators of SES in this population. The lower SES of immigrants, communication problems between doctor and patient and doctors' attitudes towards immigrants may explain ethnic differences in medical treatment after AMI.

Acknowledgements This study was supported by grants from The Danish Heart Foundation and Helsefonden.

Competing interests The authors declare that they have no conflict of interest.

\section{References}

1. Statistics Denmark (2009) Indvandrere i Danmark (Immigrants in Denmark). Copenhagen, Statistics Denmark

2. Balarajan R (1991) Ethnic differences in mortality from ischaemic heart disease and cerebrovascular disease in England and Wales. Br Med J 302(6776):560-564

3. Gadd M, Johansson SE, Sundquist J, Wandell P (2005) The trend of cardiovascular disease in immigrants in Sweden. Eur J Epidemiol 20(9):755-760

4. Harding S, Rosato M, Teyhan A (2008) Trends for coronary heart disease and stroke mortality among migrants in England and Wales, 1979-2003: slow declines notable for some groups. Heart 94(4):463-470 
5. Wild SH et al (2007) Mortality from all causes and circulatory disease by country of birth in England and Wales 2001-2003. J Public Health 29(2):191-198

6. Folmann NB, Jorgensen T (2006) Etniske minoriteter-sygdom og brug af sundhedsvæsenet (Ethnic minorities - chronic diseases and use of health care services). National Board of Health, Copenhagen

7. Rasmussen JN et al (2007) Use of statins and beta-blockers after acute myocardial infarction according to income and education. $\mathrm{J}$ Epidemiol Community Health 61(4):1091-1097

8. Thomsen RW et al (2005) Socioeconomic gradient in use of statins among Danish patients: population-based cross-sectional study. Br J Clin Pharmacol 60(5):534-542

9. Bhopal R et al (2002) Ethnic and socio-economic inequalities in coronary heart disease, diabetes and risk factors in Europeans and South Asians. J Public Health Med 24:95-105

10. Cooper H (2002) Investigating socio-economic explanations for gender and ethnic inequalities in health. Soc Sci Med 54(5):693706

11. Nazroo JY (2001) South Asian people and heart disease: an assessment of the importance of socioeconomic position. Ethn Dis 11(3):401-411

12. Winkleby MA, Kraemer HC, Ahn DK, Varady AN (1998) Ethnic and socioeconomic differences in cardiovascular disease risk factors: findings for women from the Third National Health and Nutrition Examination Survey, 1988-1994. JAMA 280(4):356-362

13. Christensen B et al (2007) Klinisk vejledning. Forebyggelse af iskæmisk hjerte-kar-sygdom i almen praksis (Clinical Guideline. Prevention of ischaemic heart disease in general practice). Danish College of General Practitioners

14. Collins R, Armitage J, Parish S, Sleigh P, Peto R (2003) MRC/BHF Heart Protection Study of cholesterol-lowering with simvastatin in 5963 people with diabetes: a randomised placebo-controlled trial. Lancet 361(9374):2005-2016
15. Freemantle N, Cleland J, Young P, Mason J, Harrison J (1999) Beta Blockade after myocardial infarction: systematic review and meta regression analysis. Br Med J 318(7200):1730-1737

16. Andrade SE, Kahler KH, Frech F, Chan KA (2006) Methods for evaluation of medication adherence and persistence using automated databases. Pharmacoepidemiol Drug Saf 15(8):565-574

17. WHO Collaborating Centre for Drug Statistics (2009) Methodology, guidelines for ATC classification and DDD assignment 2010. WHO, Oslo

18. Schouten BC, Meeuwesen L (2006) Cultural differences in medical communication: a review of the literature. Patient Educ Couns 64(1-3):21-34

19. Meeuwesen L et al (2006) Do Dutch doctors communicate differently with immigrant patients that with Dutch patients? Soc Sci Med 63(9):2407-2417

20. Weitoft GR et al (2008) Equal access to treatment? Population-based follow-up of drugs dispensed to patients after acute myocardial infarction in Sweden. Eur J Clin Pharmacol 64:417-424

21. Charles H, Good CB, Hanusa BH, Chang CC, Whittle J (2003) Racial differences in adherence to cardiac medications. J Natl Med Assoc 95(1):17-27

22. Bosworth HB et al (2006) Racial differences in blood pressure control: potential explanatory factors. Am J Med 119(1):70.e9-70. e15

23. Kressin NR et al (2007) Hypertensive patients' race, health beliefs, process of care, and medication adherence. J Gen Intern Med 22 (6):768-774

24. Uiters E et al (2006) Ethnic minorities and prescription medication; concordance between self-reports and medical records. BMC Health Serv Res 6:115

25. Madsen $M$ et al (2003) The validity of the diagnosis of acute myocardial infarction in routine statistics: a comparison of mortality and hospital discharge data with the Danish MONICA registry. J Clin Epidemiol 56(2):124-130 